\title{
Problems Analysis and Countermeasures Research on the Introduction of Overseas Chinese Talents to Colleges and Universities ----Taking Several Universities in Henan Province as Examples
}

\author{
Weidi Zhang \\ School of Foreign Languages, Henan University of Science and Technology, Luoyang Henan China \\ 471000
}

Keywords: Colleges and Universities; Returned Talents; Overseas Students; Problems; Strategy

\begin{abstract}
Talent is an important guarantee for the development of colleges and universities. The introduction of returned talents from overseas studies plays an extremely important role in enhancing the strength of universities and expanding the international influence of universities. This thesis is going to find the problems existing in the introduction of returned overseas Chinese talents to universities in Henan Province, and give some suggestions for the introduction of returned talents to universities in Henan province.

In today's world, talents are the first resource for economic and social development, especially for the high-level talents. Overseas returned talents, as one of the high-level talents, have attracted the attention of domestic universities. The introduction of returned talents from overseas countries has not only brought about talents guarantee for the development of colleges and universities, but also brought about international conveniences for their development. According to statistics from the Ministry of Education, $77.7 \%$ of the university presidents from Universities affiliated to the Ministry of Education, 84\% of academicians of the Chinese Academy of Science, $75 \%$ of academicians of the Chinese Academy of Engineering and $62 \%$ of the doctoral supervisors have the experiences of studying abroad,[1]which shows that excellent returned talents from abroad have a great positive influence on the development of colleges and universities. But for the provinces like Henan which lies in the inland of China, it is worthy of exploring how to introduce overseas returned talents and how to make full use of them after the introduction. This study will take Zhengzhou University, Henan University and Henan University of Science and Technology as examples to do the research.
\end{abstract}

\section{The Policy of Introducing Returned Talents to Universities in Henan Province}

\section{The policy in Henan Province}

In order to encourage overseas talents to work in Henan, The Henan provincial government issued "The Provisions of Encouraging Overseas Talents to Work in Henan Province" in 1992. Thereafter, in order to further attract overseas students to work in Henan, a series of official documents and policies from The Henan Provincial Government and Human Resources and Social Security Bureau of Henan province has been issued.

In 2000, the Ministry of Human Resources and Social Security of Henan Province issued " On Encouraging Overseas Talents to Return to Work in China". This document pointed out that returned talents is an important part of Chinese human resources. In 2009, Henan Province promulgated an official document "On the Introduction of Overseas High-level Talents", which says that we should catch the rare opportunity and closely combine with the actual needs of economic and social development in Henan Province to introduce more overseas high-level talents. Moreover, it proposed the plan of using 5 to 10 years to introduce about 120 high-level overseas talents. In addition, this document presented that overseas students Pioneer zones will be built. At the same time, governments in different levels as well as colleges and universities had also promulgated their respective talent policies.

In 2011, the General Office of the Henan Provincial Government issued a document "On the Establishment of a 'Green Channel' for Overseas Talents to Work in Henan", which pointed out 
that we should encourage and attract more overseas talents to work and start business in Henan province.[2]

In 2012, the Ministry of Human Resources and Social Security of Henan Province issued a document "On Speeding up the Construction of Pioneer Zones for Overseas Chinese Talents in Henan, which pointed out that we should accelerate the construction of pioneer zones so as to create a better environment for them.

\section{The policy in different universities in Henan Province}

All colleges and universities have published their own policies of introducing returned talents on the basis of these official policies. Taking Zhengzhou University and Henan University as examples, Zhengzhou University provides returned doctors research funding and family allowance and permits them to be academically promoted referring to the documents which are about the "Green Channel" for the scholars with the same academic level.[3]While Henan University stipulates that different returned talents will be given different research funding and family allowance according to their different academic fields. From 1,500,000 to 30,000,000 RMB for natural science and from 500,000 to 6,000,000 RMB for humanities and social science. In addition, Henan University will provide an apartment and academic assistants for these returned talents.

\section{The Mode of Introducing Overseas High-level Talents to Colleges and Universities in Henan Province}

Making Effective Use of National Policy. A series of policies, such as "thousand people plan" and "Yangtze River scholars", have provided convenience for the introduction of overseas high-level talents, attracting overseas high-level talents to return to work and start their own businesses. Colleges and universities of Henan province make full use of these policies to introduce overseas high-level talents. However, compared with the developed areas, there is still a big gap in the introduction of overseas high-level talents, not only in the quantity and scale of talents introduction but also in their encouragement of economic and social development, because Henan lies in the central region of China, which result in the relatively underdeveloped economy, and the reform process is relatively backward. Therefore colleges and universities in Henan province can't afford the large amount of expense in the introduction of high-level talents just as the universities in Beijing, shanghai, Guangzhou and other coastal cities. As a result, the colleges and universities have introduced far less overseas high-level talents compared with the above developed areas. According to data from Henan Overseas Students and Experts Service Center, in 2011, there were 1609 returned talents in Henan Province; in 2012, there were 2124 persons; in 2013, there are 2212 persons; [4]while, at the same time, the number of returned talents in Shanghai were 4277, 6046 and 10718 respectively.[5]

Introducing the Overseas Talents Directly by Colleges and Universities. Colleges and universities, according to their own development and talents storage plan, through the network and other media to publish recruitment notices to carry out talent introduction. This mode of introduction requires them to combine their own characteristics and favorable resources to attract overseas high-level talents.

\section{Problems of Introducing Overseas High-level Talents by Colleges and Universities in Henan Province}

Since the implementation of the "thousand people plan", all colleges and universities have been actively introducing overseas high-level talents. The introduction of high-level overseas talents provides a guarantee for the development of these universities. However, in the process of the introduction of talents, some colleges and universities just introduce them but not attract them keeping working there.

The Introduction of Talents Has Irrational Disciplinary Structure. The introduction of high-level overseas talents should be a balanced development. In fact, whether in other provinces or Henan province, the overseas high-level talents are mainly majored in science and engineering, but 
less of them are majored in the humanities and Social Sciences. [6]Taking Henan University of Science and Technology as an example, $35.82 \%$ of teachers who have the overseas experiences are majored in engineering; $8.96 \%$ of them are majored in medical science; $4.48 \%$ of them are majored in mathematics; $5.97 \%$ of them are majored in agriculture; $11.94 \%$ of them are majored in management; $8.96 \%$ of them are majored in economics; of education, art accounted for , 5.97\% of them are majored in education; $1.49 \%$ of them are majored in art; only $16.41 \%$ of them are majored in literature.

From the discipline distribution, science and engineering occupy the main share of overseas talents introduction. The proportion of Humanities and social sciences is low. From the distribution of science and engineering categories, more overseas talents are majored in applied disciplines but less of them are majored in basic Sciences. A large number of introduction of applied discipline talents will enable universities to achieve higher returns in the short term, and their contribution to scientific research and the development of disciplines will be greater. But in the long run, if the basic discipline is not stable, it will inevitably lead to the slow development of applied disciplines. The history of the development of the world university has proved that the foundation of the sustainable development of colleges and universities lies in the fact that the basic subjects are bigger and stronger, rather than the applied disciplines.[6]-2

In addition, Henan province, as the main province covered the Central Plains Economic Zone, it aims to become a national modern agriculture region and a major grain production base. It aims to become a model zone of industrialization, informatization, urbanization and agricultural modernization. It aims to be a national major economic growth region and important modern transport hub. It aims to be a Chinese history and civilization inheritance and innovation area. The tenth Party Congress of Henan Province proposed the goal and task of building an important national cultural area.[7] The construction of national cultural area is inseparable from the humanities and social sciences. It will also be an important part of the introduction of world-class talents in Humanities and social sciences from overseas countries to Henan province for colleges and universities in Henan.

It Is Irrational for Colleges and Universities to Introduce High-level Overseas Talents. With the increasingly fierce competition among college talents, there are some problems in the introduction of overseas high-level talents. The main problem is the blindness of talent introduction. Some colleges and universities are divorced from the needs of their discipline development, and the introduction of overseas talents in their research fields is quite different from the existing ones in the university. So it is difficult to form an effective research team. The modern scientific research is no longer one person's work. The contribution of a strong scientific research team is far greater than the contribution of individuals. At the same time, maintaining the corresponding echelon members can better ensure the sustainability of scientific research. Due to the lack of relevant scientific research team, the talents who has been introduced cannot perform well, so that the universities cannot get expected scientific research results. It is also a waste of human resources. All these will lead to the suspicion about the introduction of overseas high-level talents in colleges and universities. At present, the shortage of funds is common in Colleges and universities in Henan province. Therefore, how to make more effective use of the existing funds and bring in high-level overseas talents in line with the requirements of the college development is of great concern.

Limited Ability of Acceptance for the Introduction of Overseas High-level Talents. Objectively speaking, the level of social and economic development in Henan is far from that of the developed countries especially for business services, medical care, culture and education. Compared with the neighboring provinces, Henan province is not superior in the facilities mentioned above. In a short period of time it is very difficult to meet the high quality needs of returned talents from abroad, such as their children's education and their high quality life. As for overseas high-level talents, advanced experimental equipment and necessary scientific research opportunities as well as good research team are the preconditions for high-level scientific research. However, due to the location of Henan province and it's underdeveloped status of higher education, the insufficient funds of colleges and universities make the overseas high-level talents unable to obtain advanced 
experimental equipment. This situation directly and seriously influences the efficiency of overseas high-level talents' scientific research.

The Concept of Talent Introduction Is Obsolete. Because Henan is located in the Central China, the people there is relatively conservative and obsolete than those of coastal cities. So some of the leaders in Colleges and universities hold the idea that whether overseas high-level talents will be introduced and keep working here or not only depends on the economic development in this region. They believe that as long as the overseas high-level talents are well paid, they will go there successively. Excessive emphasis on the treatment of colleges and universities to these talents often leads to the neglect of their individuality. The most important characteristic of high-level talents in overseas countries lies in their personality of innovation and independence.[8]This personality determines that they would like to get more initiative to form their own research team and manage their own research funds independently rather than simply get material benefits.

Overseas High-level Talents Are Fettered by the Current System of Colleges and Universities. Colleges and universities should be organizations without government, which will maintain academic freedom and autonomy.[9]However, due to the system constraints, colleges and universities inevitably follow the traditional systematized working model. While overseas high-level talents have always been living abroad, there are some difficulties in acquiring the information.[10]After returning to China, they spend more time and energy to deal with colleges or universities administration rather than deal with teaching and academic research. So if they encounter problems such as applications of various academic projects, which involving a number of departments, they will feel difficult to work them out.[11] Colleges and universities haven't formed an integrated and systematic talent development mechanism of synchronized planning, simultaneous deployment and implementation. The mechanism of daily management and consulting services as well as information transmission for overseas high-level talents should be improved. All of the relevant functional departments of the colleges and universities should be responsible for joint management. The head of the Organization Department of the Central Committee of the CPC pointed out: "we will introduce and focus to support a number of overseas high-level scientists and leading talents who have breakthroughs in key technologies and encourage them to develop high-tech industries and improve the innovation of new disciplines in China. We will support them to start business in China." [12]It can be seen that the main purpose of the introduction of high-level overseas talents is for Chinese future of innovation and entrepreneurship. Therefore, it is necessary to free these talents from these non-research affairs so that they can devote more energy to scientific research.

\section{Strategies for the Introduction of Overseas High-level Talents in Colleges and Universities in Henan Province}

The introduction of overseas high-level talents is not only related to the management system of colleges and universities, but also closely related to the college authorities' understanding of leadership and social development.

Making Sure of the Development Goals of Colleges and Universities so as to Avoid Blind Introduction of Overseas High-level Talents. Most colleges and universities in Henan province do not have high level of development, so they should introduce overseas talents especially for high-level talents reasonably based on their practical development and their own characteristics. They should not blindly pursue the categories of disciplines, because the talent market requires the talents of various levels.[13] They should use their unique characteristics to attract more overseas high-level talents.

Balanced Introduction of Overseas High-level Talents. The purpose of introducing talents, especially for the high-level overseas talents, is not only to enhance the level of scientific research and teaching in colleges and universities, but also to bring in foreign cultures through the introduction of overseas talents. The construction of a university cannot be separated from the humanistic spirit. Balanced development between liberal arts and natural science is conducive to the comprehensive development of colleges and universities in Henan province. The cultivation of 
humanistic spirit has created important conditions for the construction of colleges and universities in Henan province.

Changing the Administration Mode of Colleges and Universities in Henan Province. It is essential to reform the current administration mode for Colleges and universities in Henan so as to keep pace with the international administration models gradually. The corresponding departments of colleges and universities are supposed to change their working methods effectively from management institutions into service organizations. They are supposed to provide better service and research environment for overseas high-level talents to encourage them work harder in China. In addition, they are supposed to establish better system to solve problems about cultural shock for the returned talents. Taking precautions in advance and keeping prompt and effective intervention and guidance for the suffered.[14]Moreover, it is significant to strengthen exchange between the returned talents and local college staff, which enable these talents to adapt to the domestic environment as soon as possible.

\section{Conclusion}

With the construction of the Central Plains Economic Zone and the establishment of Zhengzhou airlines, Zhengzhou has become a national central city, so it will be more and more competitive. It is believed that colleges and universities in Henan will also change dramatically with the development of Henan province. These changes cannot separate from high-level talents. The introduction of high-level overseas talents to colleges and universities will bring a strong impetus to the development of Henan province.

\section{Acknowledgements}

Project source: Soft Science Program of Henan Province No: 142400410384

\section{References}

[1] Information on http://www.edu.cn/fa_bu_hui_xin_xi_906/20090325/t20090325_368283_2.shtml

[2] Information on http://www.ha.hrss.gov.cn/sitegroup/root/html/4aef140825e3728f01261be1c51101b5/20120109115 130019.html

[3] Information on http://www.edu.cn/henan_82/20100312/t20100312_456383.shtml

[4] Information on http://news.hnr.cn/snxw/201402/t20140213_831084.html

[5] Information on http://www.shanghai.gov.cn/nw2/nw2314/nw24651/nw33466/nw33512/u21aw1016759.html

[6] D.K. Lu, Y. Bai, and M. Zhu: Challenges and Strategies of Overseas High-level Talent Introduction a Case Study of Qian Ren Project Fellows at Ten Universities[J].Journal of National Academy of Education Administration,2010.3,p.54

[7] Y. Wang: Reflections on Developing an Important National Culture Base[J].Party Life,2017.1

[8] Y.T. Chen, J.Y. Liu: Reflections on the Introduction of Overseas High-level Talents to Local Universities[J].Heilongjiang Researches on Higher Education,2016.9

[9] D.B. JIN,W.F. Min: Organizational Differentiation and Integration of University [J].Journal of Higher Education, 2004.1

[10] N.J. Zhou: Encyclopedia of Chinese( Volume of Media \& Publication) [M]. Beijing: The Chinese Overseas Publishing House, 1998, p565

[11] Y.P. LI,W.Guo, and Y.K. Xia: Problems and Countermeasures in the Introduction of High -level Overseas Talents in Universities[J].Journal of Southwest Agricultural University(Social Sciences Edition), 2011.5

[12] N.C. Liu, JanSadlak: World First-class Universities: Strategy, Innovation, Reform[M].Shang Hai: Shanghai Jiao Tong University Press,2009. 
[13] Z.J. Tian: Analysis of the Introduction of High-level Talents in Local Universities[J].Culture Construction,2007.5

[14] Y. Zheng: Culture Adaptation: A New Dimension of Strategies in Management of Overseas Returned Talents in Higher Education Institutions[J]. Heilongjiang Researches on Higher Education,2015.8 